\title{
PEQUEÑO CEREBRO DE AVISPA, PÁJARO RARO: EL UNIVERSO FAUNÍSTICO EN PIEL DE LOBO DE LARA MORENO
}

\author{
Elena de Pablos Trigo \\ Universidad Autónoma de Madrid \\ lna8700@gmail.com
}

\begin{abstract}
RESUMEN: Este artículo aborda el universo faunistico en Piel de lobo de Lara Moreno. Las constantes animalizaciones y los juegos narrativos con insectos y mamiferos enaltecen una obra que trata sobre la huida, la soledad, la maternidad y la familia, y que confronta, como en su novela anterior, Por si se va la luz, la urbe con el mundo rural. Los saltos temporales entre presente y pasado, y la peculiar narrativa de la autora, vertiginosa y abrupta en ocasiones, amparan una historia sórdida rebosante de secretos y silencios, la cual será enmascarada en avispas, lobos, corderos. pájaros, y tigres que se transforman en perros.

PALABRAS CLAVE: animalización, Piel de lobo, Lara Moreno, novela contemporánea, animales, siglo XXI.
\end{abstract}

\section{WASP'S LITTLE BRAIN, STRANGE BIRD: WILDLIFE UNIVERSE IN LARA MORENO'S PIEL DE LOBO}

ABSTRACT: This article discusses the wildlife universe in Lara Moreno's Piel de lobo. Zoomorphisms and narrative games with insects or mammals are frequently used to enhance this work. Piel de lobo is about a way out, loneliness, maternity and the family. It also compares the urban and the rural world as in Por si se va la luz. Lara Moreno's has an unique writing style-simple and fast-paced descriptions with temporary shifts between present and past-which improves a gloomy story full of secrets portrayed by wasps, wolves, lambs, birds and tigers able to turn into dogs.

KEYWORDS: zoomorphism, Piel de lobo, Lara Moreno, contemporary novel, animals, 21th Century.

Recibido: 14/10/2017. Aceptado: 01/05/2018 


\section{Introducción}

Piel de lobo es la segunda novela de la escritora andaluza Lara Moreno. Se publicó en el año 2016, tras el éxito de su anterior obra, Por si se va la luz (2013), ambas respaldadas por la editorial Lumen. Anteriormente escribió libros de relatos y poemarios, y participó en volúmenes colectivos como en las antologías Siglo XXI. Los nuevos nombres del cuento español actual, publicada por Menoscuarto, y Antología del microrrelato español (1906-2011), editado por Cátedra.

Sus dos novelas comparten algunos rasgos que parecen característicos de la narrativa de la autora, como el alejamiento de la urbe y el retiro de sus personajes, que se alejan de la cotidianidad. Sofía y su hijo acudirán a la casa del abuelo en la playa en la obra de 2016, mientras que Martín y Nadia se marcharán de la ciudad en la que viven y se distanciarán de sus familiares y amigos, instalándose en un pueblo con tres habitantes en la de 2013. En ambas se delibera sobre el enfrentamiento producido entre la ciudad y el mundo rural, además de cobrar gran importancia la fauna de ese nuevo espacio, con la que los protagonistas conviven. En la descripción del lugar costero de Piel de lobo y del pueblo deshabitado de Por si se va la luz se huye de paisajes idílicos.

Como señala el investigador Pozuelo Yvancos's, en la narrativa de Moreno son fundamentales las animalizaciones. En su primera novela ya estaban presentes como las comparaciones de Elena con un lagarto y con un saltamontes, y la de Zhenia, la niña que vive con Ivana, que, según la anciana, pronto se metamorfoseará en un animal: "La transformación puede llegar en cualquier momento y Elena ha de estar preparada. No es un animal cualquiera, es alguien que vigila, y eso es lo peor que puede hacer un animal. Los zorros, los lobos son así, vigilantes y enemigos". (Moreno 2013: 237-238). En Piel de lobo, este recurso se vuelve más complejo, como se examinará posteriormente. De hecho, el propio título de la última obra de la autora ya juega con la alusión a un animal como es el del mamífero carnívoro, que se podría relacionar con la sentencia lobo con piel de cordero, quizás ligada en origen a la fábula de Esopo.

Algunos críticos como Colomer consideran a Moreno una de las representantes de la corriente neorruralista de la literatura española del siglo XXI, junto con Intemperie de Jesús Carrasco o Las efímeras de Pilar Adón, que se inspira en la narrativa rural que cultivaron Miguel Delibes con Las ratas, Camilo José Cela con

1. POZUELO YVANCOS, J. M. (2016). "Formas de la distopía: Isaac Rosa, Lara Moreno y Andrés Ibáñez”. Ínsula: Revista de Letras y Ciencias Humanas 835-836: 8-11. 
La familia de Pascual Duarte o Juan Benet con Volverás a Región. Esta nueva generación de escritores recupera ese entorno rural y lo convierte en el eje de sus novelas, cobrando gran protagonismo el campo y la naturaleza. El alejamiento de la urbe implica un regreso a los orígenes, una recuperación de la esencia del ser humano y un rechazo hacia la innovación y la modernidad. No obstante, Colomer señala una diferencia fundamental que distingue a las dos generaciones:

Pero la diferencia entre aquella literatura rural y la que hoy vemos resurgir estriba en que los autores de aquel entonces habían nacido, se habían criado o habían conocido de primera mano los ambientes rurales, mientras que los escritores de la nueva hornada tienen asfalto en las venas y, por tanto, no se basan en sus propios recuerdos para ambientar sus novelas, sino que se enfrentan a la naturaleza como quien se encara a lo desconocido, a lo misterioso y, en consecuencia, a lo fascinante. Y esta relación de alteridad con lo telúrico, esta idealización del entorno rural, esta confrontación entre el cemento y lo vegetal, es precisamente lo que confiere a sus novelas un aire innovador. (Colomer 2014)

No obstante, otros críticos rechazan ese neorruralismo y abogan por una supresión de estas corrientes en la literatura contemporánea, ya que no existen rasgos determinantes y estancos para esas divisiones. Encinar y Glenn señalan la pluralidad narrativa presente en las últimas décadas, mientras que Pérès advierte de la hibridez narrativa que determina a numerosas novelas del siglo XXI como Sefarad de Antonio Muñoz Molina. En esta línea, Champeau concluye:

La diversidad y la hibridez que caracterizan las producciones artísticas en general y literarias en particular han puesto en tela de juicio corrientes literarias y modelos y hacen necesaria cierta revisión de las categorías teóricas y críticas a través de las cuales nos acercamos a la narrativa actual. (Champeau 2011: 10)

Al igual que sucede en las novelas, Valls sostiene que en el cuento español actual emerge tanto la urbe como lo rural: "En estos nuevos relatos el espacio acostumbra a ser urbano, sin que falten escenarios de ambientación rural, o los llamados no lugares, sitios donde ocasionalmente se hacina la gente, se detienen los viajeros o transcurren las vacaciones" (Valls 2011: 133). Esta situación cuestiona si realmente existe una corriente neorruralista o, simplemente, es un espacio más de la narrativa contemporánea, sumamente heterogénea.

Este artículo pretende analizar la presencia de los animales en Piel de lobo que resulta muy llamativa, debido a las frecuentes e insistentes referencias a la 
fauna; en unas ocasiones se mencionan especies de animales y, en otras, características propias de éstos. Las animalizaciones se repiten, pero a veces se trata de algo distinto como se analizará a continuación. Igualmente, son habituales las reiteraciones en la prosa de la autora, así como la supresión de los signos de interrogación y la ausencia de puntuación en determinadas ocasiones, con el objetivo de aportar velocidad a la escena y expresar, dependiendo de la situación, rabia, miedo o angustia. Su estilo narrativo es peculiar y goza de gran fuerza.

En Piel de lobo, al igual que en otras novelas, pueden aparecer asiduamente animales insertados dentro de la narración, sin que esto suponga ningún extrañamiento, o estar presentes por formar parte de la descripción de la naturaleza, como el ruido de lagartijas bajo las hojas en el noveno capítulo o contemplar bandadas de pájaros en el cielo mientras se disfruta montando en bici, como sucede en el decimoctavo episodio; también resulta usual observar gaviotas en la playa (capítulo trigésimo primero). Todas estas visiones o sonidos son esperables y no configuran una anomalía, puesto que son un elemento más de la naturaleza; sin embargo, se perciben usos curiosos de la fauna, que tienen una intención manifiesta con un significado específico, normalmente vinculado con el pasado de los personajes. En este artículo, además, se relacionan las animalizaciones que inserta Moreno con las presentes en algunas de las obras del escritor Javier Tomeo.

\section{La plaga}

La novela comienza cuando Sofía y Rita, las dos hermanas protagonistas, se encuentran en la casa de su padre, que ha fallecido recientemente, ubicada en un pueblecito costero de Andalucía. La distancia entre las hermanas y la dificultad de comunicación entre ellas se hace palpable en el primer capítulo. A lo largo de la novela se irán desvelando acontecimientos del pasado de Sofía y recuerdos de la niñez de ambos personajes hasta el amargo desenlace, en el que algunas escenas previas recobran el sentido.

Es llamativo que la ausencia o la abundancia de insectos en el hogar familiar parece determinada por el estado en el que se encuentra la hermana mayor, anclada, en un principio, a un matrimonio infeliz hasta que, al final de la novela, logra tomar las riendas de su nueva vida. Es evidente que la presencia animal ya cobra protagonismo desde el segundo capítulo: se escucha un revuelo de hormigas y cochinillas en la casa, situación esperable en una vivienda deshabitada, especialmente si está cerca del mar; la humedad y el polvo en un espacio cerrado pueden provocar que insectos penetren en el interior del domicilio. En estos 
momentos Sofía desconoce que su enlace con Julio está a punto de romperse definitivamente, pese a que la relación ya ha sufrido varios percances; paralelamente, los insectos habitan en la casa, aunque aún no se ha desatado una plaga.

Cuando Sofía es consciente del fracaso de su matrimonio, huye con su hijo Leo a la casa paterna, buscando un refugio a sus problemas. La ingesta de pastillas implica un letargo en sus sentidos, un alejamiento de las preocupaciones y un intento de posponer decisiones. Este estado de apatía, en el que se encuentra inmersa la joven, parece estar fuertemente ligado a la aparición de una plaga, originada en la cocina y en el cuarto de baño:

\begin{abstract}
Cuando llegan a casa, la encimera de la cocina es un manto negro bullicioso. Diminutas hormigas negras, distribuidas en numerosas filas, cubren la cesta con frutas, el paquete abierto de cereales, aunque sujeto con una pinza, la pequeña barra de pan de centeno envuelta en papel, que tanto trabajo le costó encontrar. Leo grita, entre el asco y la fascinación. Sofía está paralizada, no sabe qué hacer. Va al cuarto de baño a buscar alguna salvación, y al encender la luz chilla también: el mueble del baño, su bote de crema hidratante, el jabón sobre el lavabo, camino incesante de patitas, de antenas negras, el batallón indomable recorre el vaso con los dos cepillos de dientes, se mete avaricioso entre las cerdas, ávido de cualquier resto de saliva, de cualquier palabra. (Moreno 2016: 59)
\end{abstract}

Aquí se inicia una guerra por conquistar el hogar entre una de las protagonistas y los insectos. En la primera batalla, Sofía, tras creer que Julio había entrado en la casa (finalmente será su hermana) y después de escuchar al niño revivir con fascinación el episodio de las hormigas, sufre un ataque de ansiedad. Es significativo que a ella se la describa como una cobarde, el rasgo que se atribuye a la gallina: "Sofía había abierto los brazos con los codos hacia afuera, gallina de alas extendidas" (Moreno 2016: 67). Mientras tanto, se detallan cadáveres de mosquitos y hormigas gordas que se deslizan en el patio (y no en el interior del hogar), por lo que no parece haber un claro vencedor. De hecho, a causa de las drogas, se establece una tregua aparente, en la que la mujer y los insectos conviven: "Dos caladas del porro y la noche se ha suavizado, esos pequeños insectos que revolotean alrededor de la bombilla, a veces alrededor del pelo de Sofía, casi rubio bajo esa luz, con un halo de santa, de loca" (70).

La segunda batalla ocurre en los siguientes capítulos: Sofía continúa medicándose y bebiendo vino para aumentar la potencia del efecto, que provoca que caiga dormida profundamente, mientras su hijo juega solo por la casa. Esa eva- 
sión constituye una aparente victoria de los insectos, favorecida por Leo, que se zanja con el despertar de la madre ejecutando el máximo de hormigas posibles:

Leo tiene en la mano otro vaso, [...] es un vaso de cristal en movimiento [...] con una pátina de hormigas devoradoras que también se extienden por los dedos del niño, por el dorso de su mano; algunas ya desquiciadas se separan de la masa y rápidas corren hacia arriba, hacia la muñeca, el brazo que empieza a ser dorado, el codo redondo, sin punta todavía. Las hormigas, claro está, no nacen en el vaso y en la mano de Leo, sino que se desplazan en perfecta hilera por su carretera de doble sentido a través de la encimera, por los azulejos de la pared, subiendo en ángulo recto por las juntas hasta desaparecer detrás del frigorífico. Sofía debe reaccionar porque es una madre, algo le corre por las venas [...] y luego arranca de la mano de su hijo el vaso negro con cien millones de antenas y de patas y también este va al fregadero y después la mano de su hijo, las dos manos, [...] las dos manos negras debajo del grifo abierto, qué coño haces, Leo, joder, joder, y Leo está tan enfadado como su madre y por eso no llora aunque quiere llorar, ve morir a todas esas hormigas bajo el grifo, el vaso que él había llenado de miel un par de horas antes ahora limpiándose en el fregadero, su experimento abortado, su mañana silenciosa en la que nadie le hacía caso por fin, su paraíso. (Moreno 2016: 81-82)

Es evidente que el estado de conmoción de Sofía desencadena un resurgir de los invertebrados, que se apropian de la cocina en un intento por conquistar el territorio. Como madre debe salvar a su hijo de la contienda, aunque él haya generado ese caos:

Leo, cariño, no puedes jugar con las hormigas. No puedes provocarlas. No puedes invocarlas. Las hormigas están viviendo debajo de nosotros y hay tantas como no podemos imaginarnos, y tienen una especie de ciudad gigante, ya sabes cómo es, lo hemos visto en la tele y lo hemos dibujado, tienen sus túneles y sus cavernas donde están los huevos y las larvas y donde las otras hormigas llevan la comida para que se alimenten las crías, pero son tantas que podrían comernos, Leo. (Moreno 2016: 82)

La madre advierte al pequeño que es esencial que no dejen comida fuera, para no convocar a más hormigas: "[...] entran en las casas buscando la comida [...], pero no lo hacen si no dejas nada ahí, Leo, a lo mejor viene una sola, o una hilera fina de hormigas desperdigadas que apenas podemos ver, y hacen inspección, y si no encuentran nada tienen que irse a otra parte a hacer sus agujeros" (Moreno 2016: 82). Además, los biólogos Bert Hölldobler y Edward O. Wilson, 
en su obra El superorganismo, han descubierto que una cantidad de hormigas en alerta origina que aparezca aún más integrantes de la colonia, puesto que activan unas feromonas o señales químicas:

\begin{abstract}
Estos compuestos cumplen la función de alertar a las compañeras ante la presencia de enemigos cercanos o la destrucción de parte del nido. Cuando otras obreras detectan las feromonas de alarma con los receptores químicos que tienen en las antenas se desplazan hacia la fuente de alarma y una vez llegadas allí perciben que hay una concentración mayor de la feromona en cuestión y embisten con las mandíbulas abiertas para atacar con ferocidad a cualquier objeto dotado de movimiento que tenga un olor extraño. En cambio, si se encuentran con un derrumbe parcial del nido comienzan a excavar el material para liberar a las compañeras atrapadas. (2014: 162)
\end{abstract}

De ahí la dificultad de acabar con una plaga de hormigas, puesto que se comunican con facilidad ante situaciones de peligro, y la explicación por la que el número de ellas aumenta en la primera parte de la novela. En Piel de lobo, las hormigas no solo reflejan la inquietud ante el origen de una plaga, sino que también representan el miedo a lo que no se puede hacer frente, ya que puede acabar con nosotros: el personaje teme poner fin a su matrimonio y lo que eso conlleva. Ese horror e inquietud que le produce, y por el que se droga, se manifiesta en un combate contra el reino animal. Si el exterior, el patio, era antes un lugar en el que los insectos podían permanecer, Sofía, intentando recuperar el control, echa un cubo de agua con detergente sobre la tierra, como si pudiese acabar con los bichos del terreno y con el desasosiego ocasionado por la separación: "Ese pequeño trozo de tierra seca la deprime. No significa nada, porque lo significa todo. Odia profundamente ese pequeño trozo de tierra sedienta y estéril y sin sentido" (Moreno 2016: 85).

El tercer combate lo libra Sofía, en el vigésimo capítulo, cuando su hermana deja un plato de comida en la encimera y ella debe acabar con las hormigas y limpiar la cocina. Se está restableciendo emocionalmente, por lo que decide contratar a un obrero para que convierta el patio en un jardín, un intento de acercamiento hacia el reino animal, mientras permite que Leo hable con su padre, una aproximación al foco de sus problemas personales. A la par que el personaje va recuperando su fortaleza, los insectos van perdido la lucha: "A sus pies hay un par de moscas muertas, vencidas por el largo aleteo del día" (Moreno 2016: 141). 
Posteriormente, en el vigésimo tercer episodio, la madre de Leo ejecuta tareas cotidianas, sin sumirse en el sopor de las pastillas, y asume el desgaste de la relación con el padre del niño y el fin de su matrimonio, simbolizado todo ello con la intención de eliminar los insectos en la casa:

Estoy cocinando para él, limpiando el suelo de arena para él, para que sus pies no se manchen, estoy exterminando hormigas y poniendo veneno para moscas en cada rincón de este hogar de muerto, estoy todo el día ocupada en ser madre y miro a mi niño jugar, mamá, quieres jugar conmigo, y no puedo, hijo, porque tengo que hacer cosas, y tengo que pensar, y recordar, y asumir que ya está, que ya he llegado a este momento, que la vida ya no es para mí, que no me queda suficiente tiempo, que hace siglos que destruí mi libertad por pereza, por melancolía aprendida en los libros, por cobardía sobre todo, esa cobardía de buena hija que llevé a gala desde pequeña, la incapacidad para el enfrentamiento, es mucho mejor el deterioro. Es mucho más sucio el deterioro. Es mucho más letal. (Moreno 2016: 158)

Con el regreso de Rita y Paul, su nuevo novio a la casa paterna, Sofía se relaja y vuelve a drogarse; posteriormente, se marcha a la ciudad, dejando al niño con la pareja que consume asiduamente, para descansar unos días con una amiga. Los capítulos vigésimo noveno y trigésimo suponen un punto de inflexión en la historia: Rita y Paul, colocados, pierden a Leo en Portugal y el matrimonio desavenido debe regresar al sur para recuperar al niño. Este acontecimiento desencadena en varias situaciones conflictivas para los personajes: Leo se marchará con su padre, Sofía echará a Paul de la casa y comenzará a tomar las riendas de su vida, empezando por cuidar de su hermana Rita.

Este incidente, que desata el pánico de Sofía ante la posibilidad de perder a su hijo para siempre, transforma al personaje, que volverá a cocinar, a limpiar y a leer, constituyendo una victoria para el ser humano y, como ha sucedido anteriormente, una derrota para los insectos que, finalmente, desalojarán la vivienda: "Y por la noche, cuando no hay nada que hacer, con la casa limpia y la cocina recogida, ni un grano de arroz para las hormigas, las moscas durmiendo, Sofía juguetea con su móvil ya metida en la cama" (Moreno 2016: 229).

Esta plaga recuerda a la vivida en La patria de las hormigas de Javier Tomeo, en la que Blas, el dueño de la pensión, advierte al protagonista de una epidemia inminente. Así, le sugiere observar la aparición de esos pequeños insectos y utilizar el insecticida en su habitación. Las hormigas se transforman en seres terroríficos: "Se queda un momento en silencio y luego le explica que 
las hormigas, aparte de tener las mandíbulas muy afiladas, están equipadas con venenos mortales" (Tomeo 2000: 27); de hecho, el protagonista imagina situaciones sumamente inquietantes con ellas:

Supongamos por un momento - piensa - que aparecen las hormigas, que la capitana de esas hormigas prueba mi sangre y que le sabe a gloria. ¿Qué pasaría luego? No es difícil imaginarlo. Corre la voz y el ejército de hormigas se le echa encima mientras está durmiendo y le despedazan en un abrir y cerrar de ojos. (Tomeo 2000: 34)

Carmen, la sobrina de Blas, previene a Héctor que su tío se obnubiló con las hormigas hace dos meses, cuando se quedó viudo; sin embargo, el protagonista desconfía de la joven. La obsesión de los varones por estos insectos desencadena en la muerte de Carmen y en una escena en la que el lector duda si el enemigo se aproxima o si los personajes se encuentran enajenados: "Ni siquiera el coro de violines, sin embargo, le impide oír el rumor del ejército de hormigas que se aproxima lentamente por el pasillo" (Tomeo 2000: 156).

\section{Las animalizaciones}

Además del argumento central de la obra, en el que la metamorfosis de una de las hermanas está estrechamente enlazada con la plaga de insectos, se aprecian constantes menciones a la fauna con diversas interpretaciones. Se deberían destacar las animalizaciones y una serie de situaciones paralelas que evidencian lo bien cuidada que está la prosa de Lara Moreno en Piel de lobo.

En este artículo se entenderá animalización como la facultad de otorgarle a un personaje humano características propias de un animal. En palabras de Francisco Álamo Felices: "De forma inversa a la humanización o antropomorfosis y ligada a la cosificación, [...] la animalización es un proceso de caracterización en el que se atribuyen y aplican una serie de rasgos o cualidades específicas de los animales a seres humanos" (Álamo Felices 2006: 206). La animalización de los personajes, aunque es paulatina, nunca es completa ni irreversible; al final de la novela, algunos de esos rasgos del mundo animal ya no definirán a las protagonistas.

En Piel de lobo, las animalizaciones son habituales en torno al personaje de Rita, la hermana menor. Rita tiene "frente despejada de reptil, hermoso, frío" (Moreno 2016: 18) y un "pequeño cerebro de avispa, ese pájaro raro: inteligente, 
perspicaz, calmo, ausente de drama" (26). Cuando el padre, como método de castigo en la infancia, obliga a sus hijas a tirar su juguete favorito, Rita le engaña entregándole otro; entonces ella es: "como un pez volador salta una pértiga imaginaria en medio de un mar en calma, sin enfrentarse siquiera a la autoridad" (27). En todos estos casos, las animalizaciones asignan al personaje una asombrosa inteligencia.

En cambio, Sofía, la hermana mayor, posee, cuando descubre que su marido ha abandonado el hogar conyugal, "pies de rana o de pato o de salamanquesa" (Moreno 2016: 23), ejemplificando la parálisis, el desconcierto y la angustia que le produce la separación. En un encuentro de la pareja, Julio le acusa de ser una hiena: "Sofía, tú lo sabes igual que yo, joder, tú empezaste con todo esto hace mucho tiempo, no puedes seguir aferrándote a lo nuestro como una hiena a un cacho de carne muerta" (38). Como se aprecia en las citas, los sentimientos de los personajes se expresan mediante rasgos o características animales: en los ejemplos mencionados, bien por la frialdad que poseen las patas de algunos reptiles o aves, al estar en contacto con el agua, bien por el rasgo de la hiena como mamífero carroñero.

Otros ejemplos similares se aprecian en diferentes situaciones: la primera, por ejemplo, cuando Sofía debe prepararse para montar en bici, actividad que no suele realizar con asiduidad, y para la que se siente "como una morsa torpe" (Moreno 2016: 124); la segunda cuando, decaída, le gustaría salir a bailar, aunque debe quedarse en casa con el niño que: "Tiene que parecer contenta, entretenida, pero es absurdo, es una piel de serpiente abandonada en un sofá"; la tercera y última cuando, habiendo desaparecido su hijo en Portugal y presa de los nervios y la preocupación, la protagonista "se estaba revolviendo en su asiento como un gusano" (218). Los rasgos o estados en los que se encuentra el personaje son descritos con rasgos prototípicos de animales.

Las dos hermanas, definidas como alimañas en el cuarto capítulo, no son los únicos personajes a los que se les asignan atributos faunísticos. Leo, el hijo de Sofía, cuando va a la playa, "es una pulga que brinca a lo lejos" (Moreno 2016: 64) y "se le escapa como tripa de pescado, mojado y feliz" (35) a su madre cuando le intenta ajustar los manguitos. Por último, el niño posee la piel suave y tierna, rasgo que se presenta de la siguiente forma: "y la madre lo aprieta y lo acaricia detrás de las orejas, esa piel tan suave como de debajo del caparazón" (122); el caparazón no deja de ser la cubierta que protege el cuerpo de un animal. 
En ocasiones, cualquier ser humano es apto para ser animalizado, incluso personajes que no tienen ninguna importancia en la historia o que son absolutos desconocidos para éstos como los adolescentes tirados en la arena que son "brillantes lagartos sexuales, escandalosos, manoseadores" (Moreno 2016: 83) o la niña discapacitada psíquica del colegio de las hermana que tenía "labios de molusco" (90). Inclusive los objetos pueden ser animalizados, como los autobuses que "duermen cual gusanos gigantes" (19), o los líquidos como la cerveza "que le sabe a saliva de gato" (95). No existen fronteras para las animalizaciones: todo es susceptible de ser animalizado para Lara Moreno en Piel de lobo.

Las animalizaciones también son frecuentes en la narrativa de Javier Tomeo. Es especialmente interesante la obra de El cazador de leones, en la que Armando Duvalier, un supuesto cazador de esos animales, habla por teléfono con una mujer que no conoce y ambos comparan a diferentes personajes con animales como a la vecina con un hipopótamo: “¿Me dice que tiene una vecina parecida a un hipopótamo? Puede que sea un hipopótamo disfrazado de vecina" (Tomeo 2000b: 38).

La joven, pendiente del teléfono, es comparada en un inicio con un águila, por no tener familia y estar sola, para posteriormente equipararla con un animal carnívoro: "Hay mujeres que, a su modo, devoran también a los hombres. ¿Usted es una de ésas? ¿Sería usted capaz de devorarme? ¿Podría clavarme los colmillos en el cuello y dejarme sin sangre? Hágalo, hágalo ahora mismo, no pienso mover un dedo para defenderme" (Tomeo 2000b: 35). Finalmente llega el símil más acertado, ya el protagonista únicamente tiene interés en conocer al personaje femenino que no está dispuesto ni se muestra receptivo ante sus ocurrencias, convirtiéndose él en león, un animal carnívoro, y ella en gacela, su presa:

No hay todavía leones que sean capaces de hablar. [...] Lo único que hoy pueden hacer esas soberbias fieras es clavar sobre sus víctimas una mirada terrorífica, una mirada en la que puede leerse toda la desesperación que les produce el hecho de no poder entenderse tranquilamente con los demás animales de la selva. En cierto modo son víctimas de sus propias leyendas. Estoy seguro de que hay atardeceres en los que les gustaría jugar al ajedrez con alguna hermosa gacela, pero ¿dónde está esa animosa gacela que acepte a un león como compañero de juego? ¿Es usted acaso una de ellas? ¿Sería usted capaz de jugar al ajedrez conmigo, que de alguna manera soy también un león solitario? (Tomeo 2000b: 82-83)

También se debería mencionar al protagonista de La patria de las hormigas que ladra a un perro, o a la esposa de Ismael de La noche del lobo que tiene 
"cuello de cisne" o "cuello de avispa" (Tomeo 2006: 139). Los objetos, por su parte, pueden poseer cierta ánima para retrasarse o adelantarse como los relojes en La rebelión de los rábanos:

Mediodía. El tiempo pasa volando. El reloj de pared del vecino desgrana las doce campanadas sin apresuramientos de mal gusto. Una tras otra, cada una a su debido tiempo. No es, pues, uno de esos relojes nerviosos, que se adelantan al tiempo, ni tampoco de los que se retrasan porque, aunque no se atreven a detenerse del todo, se echan alguna que otra cabezadita entre minuto y minuto. (Tomeo 1999: 46-47)

Se aprecian, además, vegetales que cobran vida como las hortalizas de $L a$ rebelión de los rábanos, que inician una revuelta por independizarse del Estado común, los insectos, las aves y los mamíferos que describen sus características y algunos rasgos curiosos en Bestiario, o el ficus de La patria de las hormigas, que se encuentra en la pensión Alondra y al que el protagonista teme en cuanto descubre su presencia:

Cerca del televisor hay una maceta con un ficus de grandes hojas carnosas que parecen abrillantadas con cera. Cuidado también con esas plantas porque gastan malas pulgas. Algunas especies son carnívoras y estrangulan a los árboles que tienen cerca. Juan conoce historias de ficus que mordieron a sus jardineros. (Tomeo 2000a: 10)

Recuerda que un compañero de trabajo le contó que su ficus tenía sentimientos: "Alberto le contó que su madre tenía un ficus que se pasaba las noches llorando porque quería ser de plástico" (Tomeo 2000a: 31), incluso puede ver cómo este cambia de expresión: "Blas no hace más comentarios y se queda contemplando el ficus. Poco a poco su expresión se va haciendo más dulce, como si la planta le estuviese contando una hermosa historia. Juan, sin embargo, se estremece" (Tomeo 2000a: 99). En el desenlace, Juan desea tirar por la ventana el ficus, manifestando que es un "monstruo" (155), pero Blas no lo consiente.

El lector recela sobre la cordura de sus personajes, que parecen sufrir algún trastorno mental. Es llamativo, por ejemplo, el protagonista de El canto de las tortugas que afirma hablar con los animales ante la desconfianza y el escarnio de los vecinos del pueblo; no obstante, el lector duda de si su paranoia es real, ya que bebe a menudo y manifiesta que: "Tienen razón los que dicen que algunas veces escuchamos lo que queremos escuchar y vemos lo que queremos 
ver" (Tomeo 1998: 40), además de confesar que estuvo anteriormente encerrado en un hospital. De igual modo, se sospecha si Macario de La noche del lobo realmente escucha esas declaraciones de los cuervos.

\section{El tigre, el pájaro y el lobo}

En esta novela se hace especial hincapié en tres animales: el tigre, el pájaro y el lobo que se tratarán con más detalle, puesto que dos de ellos están íntimamente enlazados con el pasado de la hermana pequeña, Rita. El restante, el del tigre, es un aspecto de la realidad en la que se encuentra inmersa la hermana mayor, Sofía.

Las cualidades del felino son atribuibles al personaje de Sofía; así, antes de marcharse a la casa paterna, se siente "como un tigre enjaulado en la propia casa" (Moreno 2016: 42) que compartía con su marido, e insiste, mientras hace las maletas en esa idea: "la grosería del tigre encerrado en su casa, a punto de escapar, el mal olor del enjaulado" (44). En el capítulo decimoséptimo, la madre visita a las hijas y se producen momentos de tensión, previos a la discusión: "Sofía había predicho una tormenta, una como las de hace años, tres fieras enjauladas, dos contra una, siempre, nunca los mismos grupos, organización variable" (119).

El tigre aporta dos interpretaciones y dos posibles análisis. En primer lugar, el símil de la angustia por estar encerrado, sinónimo de un sentimiento asfixiante causado por una relación próxima a derrumbarse como es la de Sofía. En segundo lugar, la comparación con un animal agresivo que, normalmente, es solitario, como lo son los personajes femeninos de esta obra, y únicamente se une con otro de su especie para cazar, puesto que en pareja es más fácil engañar y arrinconar a la presa, algo que ya señala Moreno (dos contra una, siempre).

Rita es comparada en numerosas ocasiones con un pájaro. En el cuarto capítulo, en el que se narra uno de los más tempranos episodios de la niñez de las hermanas, se indica que posee un "pequeño cerebro de avispa, ese pájaro raro: inteligente, perspicaz, calmo, ausente de drama" (Moreno 2016: 26); pese a que es un ave anormal, aún no ha sufrido el acontecimiento dramático que determinará su existencia y que estalla en el desenlace de la novela. Cuando reciben la visita de la madre, en la que las tres mujeres actúan como felinos, y tras producirse el altercado, "Rita pasa por delante de su hermana sin mirarla a la cara, solo sus palabras de pájaro quedan suspendidas en la calima [...]" (120-121).

En el vigésimo episodio se reitera el mismo concepto cuando la joven se marcha de la casa de la playa y Sofía se muestra molesta por el reciente abandono: 
"Es la voz endurecida de su hermana pequeña, el pájaro violento que a veces vuela a ras, el pico afilado contra la roca, plumas apelmazadas, acaba de pasar rozándole la sien" (Moreno, 2016: 140). A ojos de la hermana mayor y en plena disputa, Rita es un ave agresiva al irse del hogar familiar, sin asumir el temor que siente a quedarse sola con su hijo. Posteriormente, cuatro capítulos después, el regreso de la hermana menor la convierte nuevamente en un pájaro: "Sofía está inmóvil, pero Rita se abalanza hacia ella, como si volara, porque al fin y al cabo es un pájaro, es inútil pretender que no existen las alas en su espalda" (171); aunque ya no es sencillamente un pájaro, ahora tiene alas.

La desaparición temporal de Leo en Portugal entraña un problema para las dos protagonistas: el niño se va con el padre, quedando Sofía sola, y Rita sufre una crisis que la mantiene en cama y que parece cercana a la depresión, aunque no se mencione explícitamente; de hecho, pierde su capacidad de conversar: "los labios de su hermana no aguijonean" (Moreno 2016: 234) y muda en un "pajarillo medio muerto" (230) o directamente "ahora no parece un pájaro" (225). Esta fase de decaimiento conduce a una pelea entre las hermanas y a que "el pájaro herido" (244) confiese haber sufrido abusos sexuales en su niñez por parte de dos primos, primero del mayor y, tiempo después, del primo pequeño. En este punto de la novela, la hermana mayor aborda una especie de monólogo en el que se culpabiliza de no haber hecho nada, de haber llegado tarde a la segunda agresión (de la primera era conocedora), de no haber ayudado al "pájaro perdido" (254), "pajarillo lacio" (255), a "la cara de un pájaro volador" (256).

El pájaro simboliza la fragilidad de una niña que sufrió abusos de familiares cuando tenía cuatro o cinco años; las cualidades del pájaro cobran sentido: era pequeña como un pájaro y fue herida para siempre. Asumir el horror acontecido en el pasado y descifrar las huellas de las agresiones en la memoria transforman a Sofía: era un tigre, un felino veloz y letal, que se metamorfosea en un simple perro:

[...] estoy temblando cuando llego a la puerta y ya no hay bolsa en mis ojos ni me late el corazón, solo tiemblo e imagino que todo ha acabado, que esas cosas pasan, que por fin nos ha pasado, no lo puedo evitar, imagino su cuerpo derramado, quieto y vencido, caído pájaro tras la cacería, yo perro que recoge, mandíbula que aprieta suavemente, para no hacer daño todavía, aunque ya no importe, caliente aún el cuerpo del pájaro entre los dientes, perro obediente que llega siempre tarde [...] (Moreno 2016: 259)

El perro ya no es un animal peligroso, sino es el que protege el cuerpo del pájaro herido. Esta figura del cadáver del ave contrasta con el pequeño cuerpo 
que no pudo, pero Sofía quisiera haber protegido, el de su hermana pequeña. Las animalizaciones no restan crueldad ni amargura a lo que se está contando y la recuperación de la primera persona refuerza la dureza del relato.

La animalización implica en algunos casos la deshumanización del personaje, es decir, de privarle de características humanas: Rita se irá deshumanizando paulatinamente a lo largo de la novela hasta llegar a la revelación y recuperarse. Si las animalizaciones eran menos relevantes en la primera parte de la obra, en la segunda se agolpan, repitiendo aquellas asociaciones que son fundamentales para su interpretación como la del pájaro o la del vuelo:

Todos los niños quieren volar (yo pensaba que no, por miedosa, pero claro que quería). Todos los niños quieren alzar los pies del suelo y gravitar, porque los pájaros lo hacen porque los insectos lo hacen porque hay algo dentro de nuestro pecho que nos tortura con la suspensión, qué tendremos de distinto los humanos, qué alojaremos ahí dentro, chatarra convulsionada, despojito milagro, qué especie de bicho alimentamos entre el tórax y la columna vertebral, que nos hace únicos, nos hace sedientos, corruptibles, niños eternos en pos del vuelo. (Moreno 2016: 111)

Rita, un pájaro herido, tampoco logrará volar simbólicamente, ya que le han arrebatado su infancia; otros niños, primos suyos, la corrompieron. Esta cita se relaciona directamente con los recuerdos del capítulo vigésimo primero, en el que el primo mayor lanza al aire a la pequeña hasta que golpea su cabeza en el techo: "Todos los niños se ríen cuando los lanzan al aire y los recogen para lanzarlos de nuevo. Así que mi hermana volaba, empujada por los brazos de nuestro primo mayor [...]" (Moreno 2016: 143). La acción de volar también se asocia con la idea de libertad, coartada por el peso del pasado.

Por último, el lobo estaría vinculado a los dolorosos recuerdos de Rita y a la sentencia de ser un lobo con piel de cordero, cuyo origen probablemente sea el de la fábula de Esopo. En el capítulo trigésimo segundo y antes de admitir los abusos, las hermanas inician un enfrentamiento: "incapaces de cuidarse la una a la otra, las dos ahí, embistiéndose, [...] le da miedo esa rueda de molino viejo en la que están metiendo sus tiernas pezuñas, cuando venga el lobo nadie sabrá reconocerlo, piel de cordero" (Moreno 2016: 244). Es evidente que el lobo llegó, abusando de la niña; cuando Sofía lo supo, se lo contó a su madre que logró que la situación parara. No obstante, un segundo lobo, disfrazado del primo menor, nunca se marchó y Sofía no lo supo reconocer. 
En el siguiente episodio, la hermana mayor llama a su madre por teléfono y comprende, sin que nadie se lo explique, todo lo ocurrido. La madre, siendo consciente de los abusos sexuales que se habían cometido contra su hija menor en varias ocasiones y por parte de dos familiares, decide silenciarlos durante décadas; Sofía se cuestiona si, interiormente, ella también suponía estas nuevas agresiones que destruyeron a su hermana:

[...] me duele el pecho de aguantar los latidos, podría colgarle el teléfono a mi madre y arrancar el coche de una vez pero no lo hago porque de alguna manera sé que todo está congelado, que nada está ocurriendo, y es ahora mi madre quien solloza al otro lado, y de pronto no puedo evitar sentir una inmensa ternura, una ternura dolorosa hacia ella, llena de espinas, un aluvión de arrepentimiento mezclado con amor, y sigo pronunciando palabras de consuelo mientras pienso en que yo he sabido esto hace unas horas, ¿o lo supe antes y no quise verlo?, ¿no debería haberlo yo sabido sin que nadie me lo dijese?, ¿no había señales suficientes?, ¿no iba el lobo vestido con su flamante piel de lobo, hosca y dura piel de lobo, jamás lobo disfrazado de cordero, lobo siempre con su lomo erizado, no aullaba el lobo a la luna delante de todos, no enseñaba sus fauces con descaro? (Moreno 2016: 258)

De acuerdo a las anécdotas que Moreno cuenta de la infancia de las niñas, es difícil entrever una agresión, aunque los hermanos se sienten atraídos por juegos macabros. Lo que es evidente es que los jóvenes, especialmente el menor, actúan como corderos, siendo auténticos lobos. La elección de ese animal no es azarosa: el lobo es carnívoro, acecha a sus víctimas, igual que los primos vigilan a la pequeña; además, este animal cazador tiene connotaciones negativas, debido a su aparición en los cuentos populares como las dos versiones de Caperucita Roja de Charles Perrault y los hermanos Grimm. La autora vincula a este animal con la idea de la familia estricta e intransigente, que no se relacionan entre ellos:

Lo que la novela plantea es que cuando se tiene al lobo dentro de casa es muy difícil defenderse, que algo terrible sucede cuando no se puede hablar con los padres de amor, de sexo, de nada; cuando aquello que te inquieta, que te preocupa, que te duele, no puedes comentarlo con la gente que más quieres. Debajo de esa incomunicación pueden surgir los horrores. (Rodríguez 2017²)

2. La periodista Emma Rodríguez realiza una entrevista a la autora en el año 2017 para Lecturas Sumergidas: $<$ https://lecturassumergidas.com/2017/02/25/lara-moreno-aprendi-mucho-de-la-sordidez-deagota-kristof/>. Las palabras citadas corresponden a una de las respuestas de Lara Moreno. 
Como señala Moreno, esta novela es una denuncia contra la incomunicación, contra los silencios, contra los secretos. Pese a una aparente felicidad en la infancia de las niñas, que se aprecia a través de los recuerdos, una sórdida historia trunca el destino de la familia para siempre; el único salvavidas es el amor que las hermanas sienten entre ellas que logra evitar que Rita se sumerja completamente en las atrocidades vividas en el pasado.

Este animal también es fundamental para Javier Tomeo en su obra La noche del lobo, en la que dos hombres se tuercen los tobillos en el bosque y, mientras llega el rescate, dialogan sobre su vida e intereses. Uno de los personajes, Macario, cree que la luna puede convertirle en hombre lobo y siente una inicial transformación en licántropo; no obstante, el otro individuo, Ismael, sospecha que su compañero está desequilibrado y no aprecia ningún cambio en él. Aún así, el primero siente cómo ese satélite le anima a que se suicide: «-También podría ser una solución que dejases en paz a ese infeliz y probases a estrangularte a ti mismo - le sugiere la luna» (Tomeo 2006: 142); pese a sus intenciones, la luna no logra su objetivo: «La luna se ríe también entre las nubes. Se siente orgullosa de sí misma, aunque esta noche, a pesar de todos sus esfuerzos, no haya conseguido transformar a Macario en un hombre lobo. Puede que lo consiga la próxima vez» (146).

La dificultad que presentan las obras de Tomeo para el lector está relacionada con la labor de discernir si las visiones y audiciones de sus personajes son veraces o si, por el contrario, todo es consecuencia de la locura que padecen sus protagonistas. A diferencia de la obra de Moreno, en la que las referencias a los animales sirven para explicar lo que el personaje oculta o calla, en las del escritor de Huesca no es así.

\section{Situaciones paralelas}

En Piel de lobo también se aprecian situaciones en las que aparece un animal, pero la interpretación de la escena es mucho más compleja; en estos casos, la presencia de animales no implica animalizaciones. Se deberían destacar especialmente tres escenas que son significativas: la mosca, el pez y las telarañas.

En el sexto capítulo, Sofía y Julio discuten sobre el final de su matrimonio, mientras una mosca intenta escapar de la habitación: "Hay un zumbido en la habitación. Se da cuenta, por fin, de que no proviene de su cerebro, sino de una mosca que, poseída, está encerrada entre el cristal y el visillo de las cortinas. La mosca, incansable y tenaz, descontrolada, lleva todo este tiempo intentando 
salir, atravesar el cristal, huir." (Moreno 2016: 40). La aparición del insecto en la escena podría tener distintas interpretaciones: en primer lugar, el animal está atrapado en un espacio cerrado, al igual que la protagonista se siente aprisionada en esa habitación y en una conversación pendiente, en la que no quiere participar, puesto que no llegará a buen puerto; en segundo lugar, el zumbido que genera el animal encerrado simboliza la densidad de la conversación en la que se encuentra sumida. En este caso, se consideran situaciones paralelas en la interpretación: es decir, el personaje se siente como el animal.

La segunda escena se encuentra en el séptimo episodio cuando Sofía llama por teléfono a su hermana para contarle que se va a divorciar. Rita no puede atenderla en ese momento, pero promete hablar después: "Julio me ha dejado, pero no pasa nada. No, no pasa nada. Sí, Rita, te estoy hablando en serio y... Está bien, sí, termina y llámame enseguida" (Moreno 2016: 48). En el transcurso entre una comunicación y otra, y a continuación de la cita anterior, se inicia una escena surrealista, en la que la hermana mayor expulsa un pez de su garganta:

Cuando cuelga el teléfono es como un gran pez, viscoso y frío, le hubiese salido por fin de la garganta. El pez boquea, ensuciándole el regazo con sus sacudidas, y luego cae a sus pies, quizá muerto. Es un pez enorme y ciego de las profundidades del mar y ahora en su garganta hay un hueco enorme y también ciego, realmente se ha abierto un boquete en su tráquea, en su laringe, en su esófago, un boquete tremendo por el que entran el aire y la saliva y la brisa nocturna, y el exceso de oxígeno le escuece, le nubla la vista. Sigue con el teléfono agarrado en una mano y con la otra se acaricia la garganta, la palpa para comprobar que de verdad no hay ningún agujero por el que esté entrando esa cantidad insoportable de aire, de salitre. (Moreno 2016: 48-49)

La escena, que se aleja del realismo, se zanja cuando la protagonista se palpa la garganta y recupera la tranquilidad. Sofía, con el teléfono en sus manos, espera nerviosa y llora angustiosamente hasta que recibe la llamada de Rita. No obstante, al final del capítulo, se recupera lo fantástico, volviendo a entrar en escena el pez:

[...] y el teléfono suena y dócilmente responde, con esa voz de hipo y de tontuna de los llantos fértiles, y llora mientras habla y el pez, ya definitivamente muerto a sus pies, la mira con sus ojos trémulos y su pátina blanca, se ha ido, Rita, me ha dejado por otra, no tengo nada, estoy sola, no sé qué voy a hacer sin él. (Moreno 2016: 49)

La irrupción de la fantástico sorprende en esta novela, aunque es obvio que está relacionada con el estado emocional de la protagonista. El pez simboliza 
el silencio que rodea al final de un matrimonio y al consecutivo inicio de un divorcio. La expulsión del animal por la garganta supone el alivio tras relatar que su relación está fracturada, y esta confesión implica una liberación para la protagonista. Posteriormente, continúa reflexionando sobre su situación, teniendo el pez idéntico significado.

En el octavo episodio, Sofía toma pastillas para dormir y le cuesta despertarse. El estado de somnolencia e irrealidad perdura durante todo el día, lo que ocasiona riñas con su hijo: "Leo no está raro porque todo esté raro, sino porque ella está rara. Es una especie de combate; consigo misma, con Leo, con las telarañas que le recubren los ojos, a veces la boca" (Moreno 2016: 55). La telaraña representa la película que, por el dolor, no le permite contemplar la realidad, ni ver lo bueno que persiste en su vida, ni hablar de ello; de ahí, que esa telilla casi transparente tape sus ojos y su boca. Además, los efectos secundarios de los tranquilizantes que ha tomado le mantienen en un estado de letargo permanente.

En La rebelión de los rábanos de Javier Tomeo también se distingue una situación paralela, en la que las hortalizas, imitando a políticos que han decidido separarse del Estado común para constituirse en una república independiente, proponen proclamar la independencia, constituirse en un Estado libre e integrarse en «una receta gastronómica que nos represente a todos» (Tomeo 1999: 8). Sin embargo, no logran llegar a un acuerdo y, por culpa de los rábanos desertores, son devoradas por caracoles. La revolución se produce tanto en la calle, protagonizada por secesionistas y patriotas, como en la cocina con el enfrentamiento entre las verduras y los rábanos. Cuando la hostilidad aumenta en el exterior, se producen las confrontaciones entre los vegetales en el interior de la casa de los Martínez.

\section{Conclusiones}

A lo largo del artículo se ha demostrado con numerosos ejemplos que el componente animal es fundamental en la última novela de Lara Moreno: desde animalizaciones a situaciones paralelas, en las que personajes e insectos pueden actuar de manera similar, o invenciones fantásticas que aportan una nueva significación a la trama.

Las protagonistas de la autora, a través de un universo faunístico, cuya elección no es azarosa, narran su realidad y sus recuerdos. La simbología y las asociaciones son poderosas y denotan una escritura muy cuidada, basada en la elección meticulosa de unos términos que intrínsecamente están ligados a otros 
conceptos. Así, para narrar una atrocidad, como es el abuso de un menor, se elige concienzudamente la figura del lobo, un animal carnívoro que ya tenía, por tradición, una connotación negativa por haber engañado y engullido a Caperucita Roja.

Piel de lobo supone una manifestación más del buen momento que goza la literatura contemporánea actual, siendo Lara Moreno, pese a su todavía corta producción novelesca, uno de sus destacados exponentes.

\section{Bibliografía}

ADÓN, P. (2015). Las efimeras. Barcelona: Galaxia Gutenberg.

ÁLAMO FELICES, F. (2006). "La caracterización del personaje novelesco: perspectivas narratológicas". Revista Signa (UNED) 15: 189-213.

ANDRES-SUÁREZ, I. (2012). Antología del microrrelato español (1906-2011): El cuarto género narrativo. Madrid: Cátedra.

BENET, J. (2004). Volverás a Región. Barcelona: Destino.

CARRASCO, J. (2013). Intemperie. Barcelona: Seix Barral.

CELA, C. J. (2012). La familia de Pascual Duarte. Barcelona: Austral.

CHAMPEAU, G. (2011). "Carta de navegar por nuevos derroteros" en Nuevos derroteros de la narrativa española actual. (Eds. G. Champeau, J. F. Carcelén, G. Tyras y F. Valls). Zaragoza: Prensas universitarias de Zaragoza: 9-19.

COLOMER, Á. (2014). "La literatura vuelve al campo" < http://www.lavanguardia.com/cultura/20140820/54413196729/literatura-campo.html>. (Acceso 27 abril 2018).

DELIBES, M. (2010). Las ratas. Barcelona: Austral.

ENCINAR, A. y GLENN, K. M. (2005). "Introducción” en La pluralidad narrativa. Escritores españoles contemporáneos (1984-2004). (Eds. A. Encinar y K. M. Glenn). Madrid: Biblioteca Nueva: 11-22.

HÖLLDOBLER, B. y WILSON, E. O. (2014). El superorganismo. Belleza y elegancia de las asombrosas sociedades de insectos. Madrid: Katz Editores.

MORENO, L. (2013). Por si se va la luz. Barcelona: Lumen.

MORENO, L. (2016). Piel de lobo. Barcelona: Lumen.

PELLICER, G. y VALLS, F. (Eds.) (2010). Siglo XXI. Los nuevos nombres del cuento español actual. Palencia: Menoscuarto.

PÉRÈS, C. (2011). "La multiplicación de las fronteras en la novela mosaico: Sefarad, de Antonio Muñoz Molina" en Nuevos derroteros de la narrativa española actual. (Eds. G. Champeau, J. F. Carcelén, G. Tyras y F. Valls). Zaragoza: Prensas universitarias de Zaragoza: 187-199. 
POZUELO YVANCOS, J. M. (2016). "Formas de la distopía: Isaac Rosa, Lara Moreno y Andrés Ibáñez”. Ínsula: Revista de Letras y Ciencias Humanas 835-836: 8-11.

RODRÍGUEZ, E. (2017). Entrevista «Lara Moreno: Aprendí mucho de la sordidez de Agota Kristof». Lecturas Sumergidas. $<$ https://lecturassumergidas. com/2017/02/25/lara-moreno-aprendi-mucho-de-la-sordidez-de-agota-kristof/>. (Acceso 10 mayo de 2017).

TOMEO, J. (2012). "Bestiario" en Cuentos completos. Barcelona: Anagrama: $27-102$.

TOMEO, J. (1998). El canto de las tortugas. Barcelona: Anagrama.

TOMEO, J. (1999). La rebelión de los rábanos. Barcelona: Destino.

TOMEO, J. (2000a). La patria de las hormigas. Barcelona: Anagrama.

TOMEO, J. (2000b) [1987]. El cazador de leones. Barcelona: Anagrama.

TOMEO, J. (2006). La noche del lobo. Barcelona: Anagrama.

VALLS, F. (2011). "Sobre el cuento español actual y algunos nuevos nombres" en Nuevos derroteros de la narrativa española actual. (Eds. G. Champeau, J. F. Carcelén, G. Tyras y F. Valls). Zaragoza: Prensas universitarias de Zaragoza: 129-162. 